\title{
Graduated, What Are Going to Do my Students?
}

\author{
Dr. Henrrik Prendushi
}

Department of Nursery/Physiotherapy, Faculty of Natural Sciences, University of Shkodra "Luigj Gurakuqi" Albania

\begin{abstract}
There are several studies carried out regarding the students 'perception of physiotherapy as study, career choice, etc, in different developed countries. In Albania, yet, it is not made a study about it and what the students want to do after finishing the bachelor. So, we considered it necessary to discover what they think about the completed university course and their future. Our study aims to know the perceptions of physiotherapy students about their studies and what they want to do after finishing the bachelor. An anonymous questionnaire was distributed to the third year, graduating, students of Physiotherapy at the University Luigj Gurakuqi in Shkodra, in their last lesson of Occupational Medicine. This study examines students' beliefs, attitudes and opinions, as well as what they expect from their profession as a physiotherapist. The questionnaire consists of three parts. The first part, general, of demographic data is made of 5 questions; the research part is made of two parts, the first one of 25 questions, some of which in the form of a 6 point Likert, and e third part is made of 5 questions all in 6 point Likert. In this paper we will present and discus the data from the demographic part and those from the second part. The questionnaire was filled out from 25 students. There is a good level of knowledge of foreign languages. All the respondent students know at least one foreign language, 23 of them knows English. 92\% of the students consider as right the choice made three years ago to study Physiotherapy. $41.2 \%$ prefer to be employed in private studios and $82.6 \%$ of students imagine that they will have a private studio, of their own, after 5 years. The majority of them like to work with adults. 80\% of them want to seek for job abroad in EU as well as in other countries. They feel prepared to work. The compliance between knowledge acquired in university with their ambitions and desires for work is estimated low, in respect of other results. They esteem their team working ability as appropriate. $92 \%$ of them wish to continue studying.
\end{abstract}

Keywords: students`attitudes, Albania, physiotherapy, emigrate abroad, choice of career.

\section{Introduction}

In many developed countries like Australia (Jones, McIntyre \& Naylor, 2010), UK (Williams et al., 2015), Canada (Öhman Solomon \& Finch, 2002), USA (Buelow, McAdams, Adams \& Rich, 2011), Sweden (Öhman, Stenlund \& Lars 2001), and others, we find a number of studies carried out regarding the students` perception of the physiotherapy as study in the university, choice of career, etc. In Albania there is not yet made a study concerning the perception of physiotherapy students about their studies and what they want to do after the bachelor. So, we considered it necessary to discover that what they think about the completed university course and their future. Students are the future of a profession. The development of the profession depends entirely on the preparedness to work of them. This study examines students' beliefs, attitudes and opinions, as well as what they expect from their profession as a physiotherapist. The study it is based in an anonymous questionnaire distributed in the last lesson of Occupational Medicine of the third year physiotherapy students, and practically at the end of the university studying course.

Occupational demand for physiotherapists is expected to growing as it is, generally, associated with the aging of the population. The aging population it is a characteristic not only for the industrialized countries but it is becoming increasingly evident even in industrializing countries (Kowal et al., 2012). It is evaluated that in the middle of the 21st century the life expectance for industrialized countries will be at about 85-87 years old (Wilmoth, 2000). Speaking with numbers, in this period, in 2050, in the world will be 2 billion people over 60 years old and 2 billion people under 15 years old, where every group will constitute $21 \%$ of the world population (Harper, 2014).
In these conditions, where aging is also associated with health problems (Chatterji et al., 2015), the need for physiotherapists in many industrialized countries is likely to continue to grow. Other consumers of the physiotherapy services in these countries, and not only, are also injured people (Wee \& Schwarz, 2004), people to rehabilitate (Winn, Chisholm, Hummelbrunner \& Hummelbrunner, 2014) and to return at work (Finger, Selb, De Bie \& Escorpizo, 2015; Johnston \& Shaw, 2013; Sheppard, Crowe, Jones \& Adams 2010), people after serious diseases (Beard $\&$ Bloom 2015; Morris et al., 2015), means, all those groups of patients which need to improve their health conditions (Khalid, Sarwar, Sarwar \& Sarwar, 2015). In response to this demand there is an increasing number of students studying physiotherapy in the universities, and the improvement of the level and methods of teaching (Gotlib et al., 2012; Jones \& Sheppard, 2008; Lapkin, Levett-Jones, \& Gilligan, 2013), too.

The choice of university study program is one of the most important life decisions. It usually defines the future career path (Jain et al., 2011; Öhman, Solomon \& Finch, 2002; Öhman, Stenlund \& Lars, 2001). Many future students analyze their career scenario considering the social status of their future profession and the opportunities for further development of it (Ayranci \& Oge, 2011; Reddan \& Rauchle, 2012; Sibson, 2011).

University studies in physiotherapy course just give a passport to enter the profession but how prepared are the students and how their gained knowledge match the needs of the labor market? In short, do they have the proper competencies and professionalism to start and to be successful (Takeuchi et al., 2008) at work? The work deals with a number of concepts as: professionalism (Mason, Vitkovitch, Lambert \& Jepson, 2016), confidence (Sole et al., 2012), and perspective. We must realize professionalism 


\section{International Journal of Science and Research (IJSR) \\ ISSN (Online): 2319-7064}

Index Copernicus Value (2015): 78.96 | Impact Factor (2015): 6.391

not only as a baggage of knowledge, whether theoretical or practical, but also as the behavior toward the patients (Cross $\&$ Sim, 2000), and the cooperation with colleagues in the team (McCallin \& BA, 2009; Neill, Hayward \& Peterson, 2007). Confidence is another important factor and it is closely related with professionalism but also with the work circumstances as the responsibility of the professionals (Clouder, 2009), the gender of the professional (DahlMichelsen, 2015; Nordholm \& Westbrook, 1985; Öhman, Solomon \& Finch, 2002), and so on. Perspective is the third important element, it is the future, is the career perception in all its aspects, ranging from economic aspect to the social position and the professional affirmation (Gotlib et al., 2012; Öhman, Stenlund \& Lars, 2001; Williams et al., 2015).

In an Australian study it is noted that to find a job in the conditions of the market saturation with physiotherapists it is not enough that the students receive high quality professional knowledge but they must also take some knowledge regarding work organization and selfmanagement skills, as well as for the application process (Jones, McIntyre \& Naylor, 2010). On the other hand features such as communication and interpersonal skills are possible to be assessed and measured (Duffy et al., 2004). In an American study there are found differences between the skills and the confidence of the students in relation with team working (Buelow, McAdams, Adams \& Rich, 2011).

Physiotherapy is new and little known in Albania. The Physiotherapy Course opened for the first time in 2006 in "Faculty of Nursing" in Tirana by a group of Belgian professors (https://fizioterapi.wordpress.com). Current data about this profession are lacking. There are no data regarding the number of jobs available as well as the number of physiotherapists in the health system, in state or private sector. Physiotherapists in private practice primarily exercise manual techniques. In the private clinics are implemented, mainly, manual techniques, exercise therapy, TENS, ultrasound therapy, etc. While in the hospitals physiotherapists are involved in Traumatology, Cardiology and Neurology Departments. Physiotherapists also exercise their profession in institutions for people with disabilities, in massage oriented beauty centers, in sport clubs and gyms.

In Albania in 2012 it is born the Albanian Association of Physiotherapists (http://www.fizioterapia.org) (AAPT) which is a member of the World Confederation for Physical Therapy (WCPT). In this association, by the WCPT data in its site, in 2016, there are 126 members (http://www.wcpt.org).

The study of physiotherapy in Albania it is done in the University System after the conclusion of the high school. University of Medicine in Tirana have a three years Bachelor study program with 1575 hours of practice (http://www.umed.edu.al), a Professional Master with a duration of 1.5 years (http://www.umed.edu.al), and a two years Scientific Master program where in the first year there are general studies, while in the second year there are studied rehabilitation methods as musculoskeletal, in neurology, in cardio respiratory, and in pediatrics (http://www.umed.edu.al). After the scientific master it can be continued with a Ph.D.
Actually, in Tirana, 1 million inhabitants, there are over 200 physiotherapy clinics. Many of these clinics belong to professionals from neighboring countries such as Italia, Macedonia, Turkey etc. Physiotherapists are part of the Order of Nursing and actually there are about 200 licensed professionals (http://www.fizioterapia.org). They are equally rewarded as the nurses (http://ijecm.co.uk).

There are some Albanian studies in different areas of the physiotherapy. They, generally, are made in the most important hospitals and in the university hospital centers. In a study done at the Hospital of Vlora results that the physiotherapy treatment sessions in patients with multiple scleroses gave positive results by improving impairment and disabilities (Allushi, Zekja, Kamberi \& Nika, 2016). The study conducted at the "Queen Geraldine" maternity in Tirana in patients, 40 women, with urinary incontinence, about the effects of combined pelvic floor muscle exercises, resulted in significant positive results of the treatment (Ndreu, Kamberi, Sinaj \& Sula, 2014). The study completed in 50 knee osteoarthritis patients evidenced significant improvements in the Kinesio Tape test after short treatment periods (Kola, Tani \& Zallari, 2016). According to another study in patients with shoulder impingement syndrome the physiotherapy treatment has proven successful (Sinaj et al., 2014). A study made in the University Hospital Center "Mother Teresa" in Tirana by a group of doctors and physiotherapists about the use of the physiotherapy for the treatment of obstetrics brachial plexus palsy (OBPP) Erb Duchenne in different aged babies with different techniques has resulted in excellent results; $70-100 \%$ functional improvement depending on the age at which the little patients have started the treatments (Vata et al., 2016). In another study completed at the same University Hospital, in the Center of Physiotherapy, about the treatment of chronic lumbagos has resulted in significant improvements in the level of the pain, muscular strength and articulated ROM (Kola, Shpata, Kola \& Nurce, 2013).

\section{Method}

In the last lesson of Occupational Medicine we have distributed an anonymous questionnaire to the students of the third year of Physiotherapy at the University Luigj Gurakuqi in Shkodra. This Physiotherapy Faculty is the result of collaboration between the University of Shkodra and University of Florence (Italy). The course consists of 34 students but at the lesson were present 25 of them, all over 18 years old. To the students was made clear that participation was voluntary and they can even consign empty or incomplete questionnaires. All the students present in the lesson completed, in just few cases with some absent data, the questionnaire. We had a compiling percentage of $100 \%(25 / 25)$ and a participation rate (calculated by the total number of the course students) of $73.5 \%$ (25/34).

The questionnaire consists of three parts. In the first part, the demographic data, there are 5 questions. The research part is made of two parts; the first one of 25 questions, some of them in the form of a 6 point Likert, and a second part, of 5 questions, all in 6 point Likert. In this paper we will present and discus the data from the demographic part and those from the first part of research. In designing the questionnaire

\section{Volume 6 Issue 7, July 2017 www.ijsr.net}




\section{International Journal of Science and Research (IJSR) \\ ISSN (Online): 2319-7064 \\ Index Copernicus Value (2015): 78.96 | Impact Factor (2015): 6.391}

we started from the idea of what we like to know from the students and it is based on and adapted from previous works (Gotlib et al., 2010; Gotlib et al., 2012).

\section{Data collection and analyses}

We commenced the processing of the questionnaires from their numbering. For analyzing the data it is been used Excel software. There was build up a table in Excel. In each column were placed the questions and the response options while each row corresponds to a compiled questionnaire. In some cases in the questionnaires there are unanswered questions, this is reflected in the Excel table as "ABSENT". In data analyzing there are calculated percentages of de facto answers to the questions.

\section{Results}

\subsection{Demographic data}

The questionnaire was completed by 19 (76\%) female and 6 (24\%) male students. The average age was 20.92 years old. All students declared that they completed the high school in 2013; in public schools 19 (79.2\%) students, and in private schools $6(20.8 \%)$ students.

In all our studies we pay a special attention to the foreign languages that our students know, but without specifying the level. It results that all the respondent students know at least one foreign language. Of which, 23 of them knows English and 23 students knows Italian. With only two foreign languages there are 10 students, mainly English + Italian. With three foreign languages there are 7 students, and with more than three foreign languages there are 5 students.

\subsection{Research data}

We grouped the questions into several groups as: about the choosing of the university study program; in regard to the work and all aspects related to it; concerning their preparedness and how much they feel able to start the work, now completed the studies; about the knowledge gained and how it comply with their wishes and ambitions; how they feel able to work in teams with other professionals; and, what about the further studies.

First, 92\% (23/25) of the students consider the choice made three years ago to study Physiotherapy as the right one.

Regarding the future employment there were some questions. First we asked them where they would prefer to be employed. From their answers, some of them multiple, resulted that $41.2 \%$ prefer to be employed in private studios, $29.4 \%$ in hospitals, $17.7 \%$ in gyms, and $11.7 \%$ at the universities. It should be mentioned that $82.6 \%$ of students imagine that they will have a private studio of their own after 5 years and just $17.4 \%$ give a negative answer to this question.

In relation of the sector where they would like to be employed, state or private, the opinions of the students are split in half, $50 \%$ for each of them.
Following, the students, $72 \%$ of them, declare that they wish to work with adults, while only $28 \%$ of them with children.

Asked in regard to their plans for seeking a job after graduation, about $60 \%$ of the students wish to try only abroad in the EU, US and other countries, about $20 \%$ want to seek job only in Albania, and about $20 \%$ in all the possible options.

For the students, $92 \%$ of them, it is difficult to find a job in Albania, while $54.2 \%$ of them think that in the EU, for physiotherapists, is not hard to find job.

The main countries where students prefer to be employed, in the EU, are: Germany with $33.3 \%$, Italy with $23.3 \%$, and the United Kingdom with $16.7 \%$, as well as some other countries. While between the countries outside the EU there are USA with $65 \%$ and Canada with $15 \%$, but as well some other countries, a little "exotic", like Dubai and Qatar, are preferred.

Looking to know how the students perceive their preparedness to start working we asked to them some questions in a 6 point Likert. Students evaluate their ability to communicate with patients at the average of 5 points.

Their level of knowledge of professional English language is esteemed in an average of 4 points.

Students esteem their ability to provide the first aid at an average of 4.20 points.

Their physical preparation necessary for working as a physiotherapist is appreciated at the average value of 4.24 points.

Students quote their ability to organize their work in efficient manner at an average value of 4.52 points.

In relation to knowledge obtained during their university studies and how it comply with their wishes and ambitions for work the students perceive themselves prepared to work at a mean value of 3.92 points.

Students estimate at 3.52 points the compliance of their knowledge acquired in university with their ambitions and desires for work.

At the end of their studies in the faculty of physiotherapy students feel themselves more capable according to fields of study: $39.5 \%$ in physical therapy, in kinesiotherapy $10.5 \%$, in massage $34.2 \%$, and in manual techniques $15.8 \%$.

Asked about the field of medicine in which they would like to work, the students have answered, in some cases in multiple answers, as: in pediatrics for $34.4 \%$ and in sports medicine for $21.9 \%$, while other areas as orthopedics, neurological, and cardiology share almost equal preferences of about $15 \%$ each of them.

Students esteem their knowledge about searching of information regarding the new practices with an average value of 4.52 points. They estimate their competencies to be 


\section{International Journal of Science and Research (IJSR) \\ ISSN (Online): 2319-7064}

Index Copernicus Value (2015): 78.96 | Impact Factor (2015): 6.391

engaged in a scientific research in an average value of 3.68 points. They appreciate their level of knowledge in medical statistics with an average value of 3.84 points.

Students esteem their ability to communicate with other members of a health team in a mean value of 4.96 points. Regarding the post bachelor studies the students have had three options to choose. $84 \%$ of them, after the bachelor, want to work and study in the same time, while just work or just study have had $8 \%$ of the preferences for each of them. With regard of the field of physiotherapy in which they would like to specialize, the respondents, in some cases in multiple answers, choose in $44.7 \%$ of the cases the physical therapy, in $23.7 \%$ massages, and in equal parts with $15.8 \%$ for each of them, kinesiotherapy and manual techniques.

\section{Discussion}

\subsection{Demographic data}

We will begin our results discussion from foreign languages that the students declared to know. The situation appears good and we think that it is related to the facts that in general Albanian people find useful to learn foreign languages, as they know that Albania is a little country and to communicate with foreigners they must know their language, or an international one. In another study completed with the pharmacists (Prendushi, 2016) we also found a good situation, too. Secondly, as results, from the present study, $60 \%$ of them after graduating will seek employment just abroad, another $20 \%$ in all the options (means, we have $80 \%$ of our students looking for employment abroad) and $20 \%$ of them just in Albania.

\subsection{Research data}

First, 92\% (23/25) of students consider as the right choice that one made three years ago to study Physiotherapy. The same result, $92 \%$, we find in a master thesis made in Bangladesh (Sarkar, 2012). In a study conducted in Poland it is shown that $70 \%$ of students are satisfied from their physiotherapy choice (Gotlib et al., 2010). As well, in another study made in the UK it is shown that all the participants graduated in a clinically based program, during a 10 year period, continue to work in the field of physiotherapy (Green, Perry \& Harrison, 2008).

The beginning of the work is the final scope of the study for the students. To understand the views and objectives of the students for this aspect we have asked them some questions. First we asked where they would prefer to be employed. From the answers, often multiple, result that $41.2 \%$ of them prefer to be employed in private studios, $29.4 \%$ in hospitals, $17.7 \%$ in gyms, and $11.7 \%$ at the university. It is very interesting and it should be noted that $82.6 \%$ of students think that they will have a private studio, of their own, after 5 years and just $17.4 \%$ give a negative answer to this question. An Australian study shows that young graduates do not have the appropriate level of knowledge to make private activity (Davies, Edgar \& Debenham, 2016) immediately after graduated. This, generally, corresponds to the statement made by our students because they think they will have their own studio after 5 years of exercising.
As regards the sector where they would like to be employed, state or private, the opinions of the students are divided in half, $50 \%$ for each of them. This response is in line with the logical process of the answers where nearly $50 \%$ of students are expressed that they wish to work in a private studio. Following, $72 \%$ of the students say that they wish to work with adults, while $28 \%$ with children. A Canadian study shows, too, that the majority of the students prefer to work in private practice and with adults (Öhman, Solomon \& Finch, 2002).

Concerning the job seeking after graduation, there are about $60 \%$ of students who wish to work only abroad in the EU, US and in other countries, about $20 \%$ want to seek for job only in Albania and about $20 \%$ in all the possible options. In contrast, an Indian study shows that $59 \%$ of the students prefer to work in India and only $14 \%$ prefer to emigrate (Jain et al., 2011).

Speaking about the possibility of finding the job, for $92 \%$ of the students it is difficult to find a job in Albania, while $54.2 \%$ of them think that in the EU for physiotherapists it is not difficult to find work. Similar data results from a study conducted in Poland where $72 \%$ of the students affirm that it is difficult to find a job as physiotherapist in Poland while for $80 \%$ of them it is easy in the EU (Gotlib et al., 2010). Even physiotherapy students from England and Spain believe that it is easier to find a job in other EU countries (Gotlib et al., 2012).

The main EU countries where students prefer to find employment are Germany with $33.3 \%$, Italy with $23.3 \%$, and United Kingdom with $16.7 \%$. While outside EU there are USA with $65 \%$ and Canada with $15 \%$. In a Polish study it turns out that $70 \%$ of students graduated in physiotherapy want to seek work abroad, mainly in Germany and England (Gotlib et al., 2010).

We asked to the students some questions about their preparedness to work, all of them to be quoted in a 6 point Likert. Students appreciate with a mean value of 5 points their ability to communicate with patients; $\mathrm{CV}=24 \%$ and MODA $=6$. This means that according to the students esteem their level of communication ability with the patient is high. In a study completed in Australia with last year students of paramedics it turns out that those resulted in different responses, by the fields, that range from 'somewhat adequately' to 'adequately' (O'Brien, Moore, Hartley \& Dawson, 2013). A Polish study shows that $67 \%$ of students look at themselves as well prepared to start working (Gotlib et al., 2010). But a Canadian study shows that the students do not give the due priority to patients with different problems for physiotherapy treatment (Laliberte \& Ehrmann Feldman, 2013). In an Australian study are found clear difference in the skills to work with difficult patient between young and experienced physiotherapists (Potter, Gordon \& Hamer, 2003a). Another Australian study, with the aim of assessing the work and the communication skills of physiotherapists from the patient's point of view, shows that the physiotherapist ability to communicate is ranked in the first place by the patients (Potter, Gordon \& Hamer, 2003b).

\section{Volume 6 Issue 7, July 2017 www.ijsr.net}




\section{International Journal of Science and Research (IJSR) \\ ISSN (Online): 2319-7064}

Index Copernicus Value (2015): 78.96 | Impact Factor (2015): 6.391

Professional English language knowledge is esteemed by the students with 4 points; $C V=40 \%, M O D A=6$. This should be looked as an important element remembering that the majority of students prefer to work abroad. In this question we have to consider the fact that in this group there are two students who have declared that they don't understand English, which lowers the mean value and increase the coefficient of variation (CV) at $40 \%$.

Students esteem their ability to provide the first aid in 4.20 points, as mean value, $\mathrm{CV}=29 \%$ and $\mathrm{MODA}=5$. Even here we have generally satisfactory statistical figures, especially if we look at the most declared value in the answers, MODA, which is 5 points. In a study done in the Netherlands in a theoretical and practical test regarding first aid and basic life support of junior doctors the results showed that their preparation resulted inappropriate in front of the standards of the country (Tan et al., 2006). In a UK study with students of the healthcare professions about the ability to check the carotid pulse, as part of first aid, result that only 38\% reached the required standard (Moule, 2000). Here we must mention that our good results belong to students`self-estimation but the non appropriate results, in the other countries, belong to test data!

Necessary physical preparation for working as a physiotherapist is evaluated by our students in an average value of $4.24, \mathrm{CV}=26 \%$ and $\mathrm{MODA}=5$. Even in a study made in Poland it turns out that the students have given similar answers (Gotlib et al., 2010). Students appreciate their ability to organize their work efficiently at a mean value of $4.52, \mathrm{CV}=29 \%$, and $\mathrm{MODA}=5$.

In relation to the knowledge gained in the university and how much it comply with their wishes and ambitions for working the students perceive themselves prepared to work

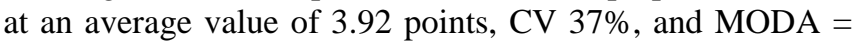
3. In an Australian study it is shown that the paramedic students esteem their readiness for work depending on the different subjects and their general self-esteem for work as 'somewhat adequately' to 'adequately' (O'Brien, Moore, Hartley \& Dawson, 2013).

Students appreciate the compliance of their knowledge acquired in the university with their ambitions and desires for work with 3.52 points as average, $\mathrm{CV}=36 \%$ and MODA $=4$. In the terms of the compliance between theory and practice in a UK study is shown that there is an apparent discrepancy between theory and practice in physiotherapy students while in nursing the situation is better (Roskell, Hewison \& Wildman, 1998). An Australian study clearly evidence the need to increase compliance among what is gained at the university and what the physiotherapists will come across in practice (Hunt, Adamson \& Harris, 1998).

On completion of university studies in the faculty of physiotherapy students feel themselves more capable in some areas and less in others. Physical therapy and massage for $39.5 \%$ and $34.2 \%$ of the students, respectively, are the areas where they feel more prepared, while in manual techniques just for $15.8 \%$ of the students, and in kinesiotherapy for $10.5 \%$ of them. This mean that maybe there is a need for improvement in some areas. In a review of studies about the ways of teaching in physiotherapy results that the problem based learning can be considered as a more effective method than classical but there are no clear conclusions. On the other hand it is shown that in general the faculty of physiotherapy needs to change the way of teaching (Karthikeyan, Moorthy, Dhargave \& Venkatesh, 2015; Solomon, 2005).

Students esteem their ability to communicate with other members of a health team with 4.96 points, $\mathrm{CV}=26 \%$, MODA $=6$. In a study made in Australia and New Zealand results that it is expected that the professionals coming out from the university have their role and professional competence within a team with different professionals (Crosbie et al., 2002; Dufour, Lucy \& Brown, 2014).

Asked about the field of medicine in which they would like to work it turns out, in some cases in multiple answers, that the students main choice belongs to pediatrics with $34.4 \%$ and then $21.9 \%$ of the sports medicine. While other selected areas as orthopedics, neurological and cardiology have nearly in equal proportion about $15 \%$ for each of them. An Australian study shows that the physiotherapists which in the first years of their career are been working in pediatrics are the most satisfied with their work, while those working in cardiology (Bacopanos \& Edgar, 2016) are the less satisfied. In another study is addressed the importance of the role of the physiotherapist in sports medicine and in general for physical activity and health (Singh \& Education, 2013).

Students esteem their ability to require information regarding the new practices with 4.52 points as average, $\mathrm{CV}$ $=29 \%$ and MODA $=5$. They appreciate their competencies to be engaged in a scientific research by an average of 3.68 points, $\mathrm{CV}=27 \%$, MODA $=4$. Students esteem their level of knowledge of medical statistics in an average of 3.84 points, $\mathrm{CV}=29 \%$, MODA $=4$. An Australian study shows that there is a shortage of research work in the hospitals where the physiotherapists exercise and this is mainly related to the workload and the lack of time, but as driving factors for research are identified the growth of professional skills and the job satisfaction (Skinner, Williams \& Haines, 2015). In a review the possibility of growing research in health organizations is thought to be improved through the creation of specific research roles within these organizations (Wenke \& Mickan, 2016).

Regarding the post bachelor studies $84 \%$ of the students have stated that after bachelor they want to work and study in the same time, while just working and just studying has $8 \%$ for each one. An Indian study shows that $87 \%$ of the students wish to continue the post-graduate studies (Jain et al., 2011), while a UK study shows that the master studies have a positive impact over the physiotherapist career (Green, Perry \& Harrison, 2008).

With regard of the field of physiotherapy in which the students would like to specialize, even here with some multiple answers, in $44.7 \%$ of cases they choose the physical therapy, in $23.7 \%$ massage, and equally with $15.8 \%$ kinesiotherapy and manual techniques. A Polish study shows that massage and kinesiotherapy are among the favorites for a further training with $76 \%$ and $81 \%$, respectively (Gotlib et

\section{Volume 6 Issue 7, July 2017 www.ijsr.net}




\section{International Journal of Science and Research (IJSR) \\ ISSN (Online): 2319-7064 \\ Index Copernicus Value (2015): 78.96 | Impact Factor (2015): 6.391}

al., 2010). In an Australian study the specialization in physiotherapy is considered as a mark of maturity for the professionals (Bennett \& Grant, 2004).

\section{Conclusions}

Knowledge of foreign languages is in an adequate level but seeing that the most of the students think to be employed outside leaves a bitter taste.

Most of the students at the end of three years are satisfied from their chosen profession.

More interesting is the fact that at least half of the students choose to work in the private sector, and most of them imagine that after five years will have their studios, although the most of them intend to emigrate. It makes us think that in their migration plans may be the private initiative in the countries where they wish to go.

Students believe that it is difficult to find work for their profession in Albania while for more than one half of them in other countries it is more possible. Students preferences to emigrate in the EU countries belong mainly to Germany and Italy; while outside EU belong to USA and Canada.

In general, students are confident in their abilities and this is reflected in the estimates they give about many aspects of their future work.

The lower values obtained from the answers of the students are about the compliance between the knowledge gained during their studies and the future work activity.

Most of the students express their wish to continue with further studies.

\section{Limitations}

The main limitation is related to the modest number of students, but that is because of the dimensions of physiotherapy course.

\section{Acknowledgements}

I thank the students who filled out the questionnaire.

\section{References}

[1] Allushi, E., Zekja, I., Kamberi, F., \& Nika, S. (2016). Clinical Case Studies Of The Multiple Scleroses Patients In Vlora Hospital During January-December 2015. European Scientific Journal.

[2] Ayranci, E., \& Oge, E. (2011). A Study of the Relationship between Students' Views toward A Career Management Class and Their Future Careers. International Business Research, 4(1), 198.

[3] Bacopanos, E., \& Edgar, S. (2016). Identifying the factors that affect the job satisfaction of early career Notre Dame graduate physiotherapists. Australian Health Review.
[4] Beard, J. R., \& Bloom, D. E. (2015). Towards a comprehensive public health response to population ageing. Lancet (London, England), 385(9968), 658-661.

[5] Bennett, C. J., \& Grant, M. J. (2004). Specialisation in physiotherapy: a mark of maturity. Australian Journal of Physiotherapy, 50(1), 3-5.Buelow, J. R., McAdams, R., Adams, A., \& Rich, L. E. (2011). Interdisciplinary teamwork: student differences and teaching implications. American Journal of Health Sciences (AJHS), 1(1).

[6] Chatterji, S., Byles, J., Cutler, D., Seeman, T., \& Verdes, E. (2015). Health, functioning, and disability in older adults - present status and future implications. The Lancet, 385(9967), 563-575.

[7] Clouder, L. (2009). 'Being responsible': students' perspectives on trust, risk and work-based learning. Teaching in Higher Education, 14(3), 289. 301.

[8] Crosbie, J., Gass, E., Jull, G., Morris, M., Rivett, D., Ruston, S., ... \& Wright, T. (2002). Sustainable undergraduate education and professional competency. Australian Physiotherapy, 48(1), 5-7.

[9] Cross, S., \& Sim, J. (2000). Confidentiality within physiotherapy: perceptions and attitudes of clinical practitioners. Journal of Medical Ethics, 26(6), 447453.

[10] Dahl-Michelsen, T. (2015). Gender in physiotherapy education. A study of gender performance among physiotherapy students and changes in the significance of gender.

[11]Davies, J. M., Edgar, S., \& Debenham, J. (2016). A qualitative exploration of the factors influencing the job satisfaction and career development of physiotherapists in private practice. Manual Therapy.

[12] Duffy, F. D., Gordon, G. H., Whelan, G., Cole-Kelly, K., \& Frankel, R. (2004). Assessing competence in communication and interpersonal skills: the Kalamazoo II report. Academic Medicine, 79(6), 495-507.

[13] Dufour, S. P., Lucy, S. D., \& Brown, J. B. (2014). Understanding Physiotherapists' Roles in Ontario Primary Health Care Teams. Physiotherapy Canada, 66(3), 234-242.

[14] Finger, M. E., Selb, M., De Bie, R., \& Escorpizo, R. (2015). Using the International Classification of Functioning, Disability and Health in physiotherapy in multidisciplinary vocational rehabilitation: A case study of low back pain. Physiotherapy Research International, 20(4), 231-241.

[15] Gotlib, J., Białoszewski, D., Opavsky, J., Garrod, R., Fuertes, N. E., Gallardo, L. P., ... \& Kunicka, I. (2012). Attitudes of European physiotherapy students towards their chosen career in the context of different educational systems and legal regulations pertaining to the practice of physiotherapy: implications for university curricula. Physiotherapy, 98(1), 76-85.

[16] Gotlib, J., Białoszewski, D., Sierdziński, J., Jarosz, M. J., Majcher, P., Barczyk, K., ... \& Kułak, W. (2010). A comparison of the perceptions and aspirations of thirdyear physiotherapy students trained in three educational settings in Poland. Physiotherapy, 96(1), 30-37.

[17] Green, A., Perry, J., \& Harrison, K. (2008). The influence of a postgraduate clinical master's 


\section{International Journal of Science and Research (IJSR) \\ ISSN (Online): 2319-7064}

Index Copernicus Value (2015): 78.96 | Impact Factor (2015): 6.391

qualification in manual therapy on the careers of physiotherapists in the United Kingdom. Manual Therapy, 13(2), 139-147.

[18] Harper, S. (2014). Economic and social implications of aging societies. Science, 346(6209), 587-591.

[19] http://ijecm.co.uk/wp-content/uploads/2015/07/3735.pdf (October 2016)

[20] http://www.fizioterapia.org/(October 2016)

[21] http://www.fizioterapia.org/?p=1062 (October 2016)

[22] http://www.umed.edu.al/fakultetet/fakulteti-ishkencave-mjekesore-teknike/programet-estudimit.html\#mastershk (October 2016)

[23] http://www.umed.edu.al/fakultetet/fakulteti-ishkencave-mjekesore-teknike/programet-estudimit.html\#masterpro (October 2016)

[24] http://www.umed.edu.al/images/Programet/FSHMT/Ba chelor/Bachelor-Fizioterapi.pdf (October 2016)

[25] http://www.wcpt.org/node/48619 (October 2016)

[26] https://fizioterapi.wordpress.com/about/ (October 2016)

[27] Hunt, A., Adamson, B., \& Harris, L. (1998). Physiotherapists' perceptions of the gap between education and practice. Physiotherapy Theory and Practice, 14(3), 125-138.

[28] Jain, R. A. S. H. M. I., Menezes, R. G., Chawla, P. O. O. J. A., Rao, P. J., Kotian, M. S., \& Jain, A. N. I. M. E. S. H. (2011). Career choice among physiotherapy students at Mangalore, India. J Clin Diagn Res, 5, 3446.

[29] Johnston, V., \& Shaw, W. S. (2013). Helping workers help themselves: empowering physiotherapy clients to manage musculoskeletal problems at work. Physical Therapy Reviews, 18(5), 373-378.

[30] Jones, M., McIntyre, J., \& Naylor, S. (2010). Are physiotherapy students adequately prepared to successfully gain employment?. Physiotherapy, 96(2), 169-175.

[31]Jones, A., \& Sheppard, L. (2008). Physiotherapy education: a proposed evidence-based model. Advances in physiotherapy, 10(1), 9-13.

[32] Karthikeyan, T., Moorthy, A., Dhargave, P., \& Venkatesh, N. (2015). Pre and Post Informal Training Evaluation of the Performance Skills among Physitherapy Students. Indian Journal of Physical Therapy, 2(2).

[33] Khalid, M. T., Sarwar, M. F., Sarwar, M. H., \& Sarwar, M. (2015). Current role of physiotherapy in response to changing healthcare needs of the society. International Journal of Education and Information Technology, 1(3), 105-110.

[34] Kola, I., Shpata, V., Kola, S., \& Nurce, A. (2013). Treatment of Chronic Lumbagos Through Rehabilitation.

[35] Kola, I., Tani, K., Zallari, K., (2016) Physiotherapy effects on gait speed in patients with knee osteoarthritis.

[36] Kowal, P., Chatterji, S., Naidoo, N., Biritwum, R., Fan, W., Ridaura, R. L., ... \& Snodgrass, J. J. (2012). Data resource profile: the World Health Organization Study on global AGEing and adult health (SAGE). International journal of epidemiology, 41(6), 1639-1649.

[37] Laliberte, M., \& Ehrmann Feldman, D. (2013). Patient Prioritization Preferences among Physiotherapy Entry-
Level Students: The Importance of Chronic Pain. Physiotherapy Canada, 65(4), 353-357.

[38]Lapkin, S., Levett-Jones, T., \& Gilligan, C. (2013). A systematic review of the effectiveness of interprofessional education in health professional programs. Nurse education today, 33(2), 90-102.

[39] Mason, R., Vitkovitch, J., Lambert, R., \& Jepson, J. (2016). Knowing about and performing professionalism: Developing professionalism in interprofessional healthcare education. International Journal of Practice-Based Learning in Health and Social care, 2(1), 96-107.

[40] McCallin, A., \& BA, R. (2009). Factors influencing team working and strategies to facilitate successful collborative teamwork. NZ Journal of Physiotherapy, 37(2), 62.

[41] Morris, J. H., Oliver, T., Kroll, T., Joice, S., \& Williams, B. (2015). From physical and functional to continuity with pre-stroke self and participation in valued activities: A qualitative exploration of stroke survivors', carers' and physiotherapists' perceptions of physical activity after stroke. Disability and rehabilitation, 37(1), 64-77.

[42] Moule, P. (2000). Checking the carotid pulse: diagnostic accuracy in students of the healthcare professions. Resuscitation, 44(3), 195-201.

[43] Ndreu, V., Kamberi, F., Sinaj, E., \& Sula, A. (2014) Effects of Combined Pelvic Floor Muscle Exercises in Patient with Urinary Incontinence.

[44] Neill, M., Hayward, K. S., \& Peterson, T. (2007). Students' perceptions of the interprofessional team in practice through the application of servant leadership principles. Journal of Interprofessional Care,21(4), 425-432.

[45] Nordholm, L. A., \& Westbrook, M. T. (1985). Career development of female physiotherapists: Stage four of a longitudinal survey. Australian Journal of Physiotherapy, 31(1), 10-17.

[46] O’Brien, K., Moore, A., Hartley, P., \& Dawson, D. (2013). Lessons about work readiness from final year paramedic students in an Australian university. Australasian Journal of Paramedicine, 10(4).

[47] Öhman, A., Solomon, P., \& Finch, E. (2002). Career choice and professional preferences in a group of Canadian physiotherapy students. Advances in physiotherapy, 4(1), 16-22.

[48] Öhman, A., Stenlund, H., \& Lars, D. (2001). Career choice, professional preferences and gender? The case of Swedish physiotherapy students. Advances in physiotherapy, 3(3), 94-107.

[49] Potter, M., Gordon, S., \& Hamer, P. (2003a). The difficult patient in private practice physiotherapy: A qualitative study. Australian Journal of Physiotherapy, 49(1), 53-61.

[50] Potter, M., Gordon, S., \& Hamer, P. (2003b). The physiotherapy experience in private practice: the patients' perspective. Australian Journal of Physiotherapy, 49(3), 195-202.

[51] Prendushi, H. (2016). The Attitudes and Practices of Albanian Pharmacists Regarding Complementary Medicinal Products and Supplements. Imperial Journal of Interdisciplinary Research, 2(8). 


\section{International Journal of Science and Research (IJSR) \\ ISSN (Online): 2319-7064}

Index Copernicus Value (2015): 78.96 | Impact Factor (2015): 6.391

[52] Reddan, G., \& Rauchle, M. (2012). Student perceptions of the value of career development learning to a workintegrated learning course in exercise science. Australian Journal of Career Development, 21(1), 38-48.

[53] Roskell, C., Hewison, A., \& Wildman, S. (1998). The theory-practice gap and physiotherapy in the UK: insights from the nursing experience. Physiotherapy Theory and Practice, 14(4), 223-233.

[54] Sarkar, Y. A. (2012). Perception of physiotherapy students regarding to their profession (Doctoral dissertation, Department of Physiotherapy, Bangladesh Health Professions Institute, CRP).

[55] Sheppard, L. A., Crowe, M., Jones, A., \& Adams, R. (2010). A model for re-education of physiotherapy practitioners to enable return to the workforce(Doctoral dissertation, New Zealand Society of Physiotherapists).

[56] Sibson, R. (2011). Career choice perceptions of undergraduate event, sport and recreation management students: An Australian case study. Journal of Hospitality, Leisure, Sports and Tourism Education (Pre-2012), 10(2), 50.

[57] Sinaj, E., Ndreu, V., Kamberi, F., Cina, T., \& Sinaj, E., (2014). Results of combined physiotherapy in patients with clinical sings of shoulder impingement syndrome: a randomized controlled trial.

[58] Singh, S., \& Education, P. (2013). Physiotherapy in Sports: An Empirical Study and Analysis. Physiotherapy, 4(1).

[59] Skinner, E. H., Williams, C. M., \& Haines, T. P. (2015). Embedding research culture and productivity in hospital physiotherapy departments: challenges and opportunities. Australian Health Review, 39(3), 312314.

[60] Sole, G., Claydon, L., Hendrick, P., Hagberg, J., Jonsson, J., \& Harland, T. (2012). Employers' perspectives of competencies and attributes of physiotherapy graduates: an exploratory qualitative study. NZJ Physiother, 40(3), 123-7.

[61] Solomon, P. (2005). Problem-based learning: a review of current issues relevant to physiotherapy education. Physiotherapy theory and practice, 21(1), $37-49$.

[62] Takeuchi, R., O'Brien, M. M., Ormond, K. B., Brown, S. D., \& Maly, M. R. (2008). "Moving forward": success from a physiotherapist's point of view. Physiotherapy Canada.

[63] Tan, E. C., Severien, I., Metz, J. C., Berden, H. J., \& Biert, J. (2006). First aid and basic life support of junior doctors: A prospective study in Nijmegen, the Netherlands. Medical teacher, 28(2), 189-192.

[64] Vata, L., Gradica, F., Vata, D., Pistulli, E., \& Hyseni, H. H. (2016). Physiotherapy Treatment of Obstetrics Brachial Plexus Palsy (OBPP) Erb-Duchenne by Age Group. Anglisticum Journal, 5(9), 24-28.

[65] Wee, J., \& Schwarz, R. (2004). An international comparative study assessing impairment, activities, and participation in spinal cord injury rehabilitation-a pilot study. Asia Pacific Disability Rehabilitation Journal, 15(2), 43-53.

[66] Wenke, R., \& Mickan, S. (2016). The role and impact of research positions within health care settings in allied health: a systematic review. BMC Health Services Research, 16(1), 355.

[67] Williams, A., Norris, M., Cassidy, E., Naylor, S., Marston, L., \& Shiers, P. (2015). An investigation of the relationship between ethnicity and success in a BSc (Hons) Physiotherapy degree programme in the UK. Physiotherapy, 101(2), 198-203.

[68] Wilmoth, J. R. (2000). Demography of longevity: past, present, and future trends. Experimental gerontology, 35(9), 1111-1129.

[69] Winn, C. S., Chisholm, B. A., Hummelbrunner, J. A., \& Hummelbrunner, C. W. B. C. J. (2014). Factors affecting recruitment and retention of rehabilitation professionals in Northern Ontario, Canada: a crosssectional study. Rural Remote Health, 14, 2619. 